\title{
PERSPECTIVA SOCIOAMBIENTAL NO DISCURSO JORNALÍSTICO DO SITE DA AGÊNCIA AMAZÔNIA REAL
}

\section{SOCIO-ENVIRONMENTAL PERSPECTIVE IN THE JOURNALISTIC DISCOURSE ON THE WEBSITE OF THE AMAZÔNIA REAL AGENCY}

\section{Ingrid Gomes Bassi ${ }^{1}$}

${ }^{1}$ Universidade Federal do Sul e Sudeste do Pará, Instituto de Ciências Sociais Aplicadas, Faculdade de Comunicação, Brasil. ingrid.bassi@unifesspa.edu.br

\section{A R TICLE INFO}

Article history:

Received 2020-03-24

Accepted 2020-06-20

Available online 2020-06-20
Palavras-chave: Agência Amazônia Real. Alteridade. Análise Hermenêutica de Profundidade. Discurso Jornalístico. Socioambiental.

Keywords: Amazônia Real Agency. Alterity. Depth Hermeneutic Analysis. Journalistic Discourse. Socioenvironmental.

RESUMO. O presente artigo pretende analisar o site da Agência de Notícias Amazônia Real sobre o conceito discursivo socioambiental, com o corpus de análise do mês de fevereiro de 2019. Foram utilizados os métodos de pesquisa Hermenêutica de Profundidade (THOMPSON, 2011) aliado à Análise de Discurso (ORLANDI, 2010; MACHADO \& JACKS, 2001). No artigo também é resumido o contexto histórico da Agência, por meio de entrevistas com representante do meio de comunicação. Como resultados e discussão identificaram-se o uso de fontes primárias e testemunhais na produção jornalística, complementando e prospectando o contexto sócio histórico dos fatos analisados. Nas considerações finais verificaram-se embasamento cultural da identidade de território, assim como procuraram desenvolver o discurso jornalístico à luz da alteridade, além de problematizarem em interpretações discursivas críticas as complexidades sobre o contexto socioambiental na região amazônica, a partir do olhar narrativo desses atores costumeiramente subalternizados pela grande imprensa.

\begin{abstract}
The present paper intends to analyze the website of the news agency Real Amazon about the discursive concept socio-environmental, with the corpus of analysis for the month of in February of 2019. The research methods used were Depth Hermeneutics (Thompson, 2011) and Discourse Analysis (ORLANDI, 2010; MACHADO \& JACKS, 2001). The article also summarizes the historical context of the Agency, through interviews with representative of the media. As results and discussion, we identified the use of primary and testimonial sources in the journalistic production, complementing and prospecting the socio-historical context of the analyzed facts. In the final considerations, we verified the cultural basis of the territory identity, as well as they tried to develop the journalistic discourse in the light of alterity, besides problematizing in critical discursive interpretations the complexities about the context socio-environmental in the Amazon region, from the narrative look of these actors who are usually subalternated by the mainstream press.
\end{abstract}

\section{Introdução}

Nosso local de fala, traz o território amazônico, o qual é deflagrado atualmente por disputas de territórios em razão de comunidades locais (tradicionais, quilombolas, indígenas e outras mestiçagens) estarem diante de emblemáticas socioambientais, colocadas por grandes empresas de mineração, exploração de hidrelétricas, construção de ferrovias, estradas, portos e urbanizações sem planejamento e incorporação adequada pelos poderes públicos e 
privados. Somado ao nosso contexto socioambiental e econômico destacam-se as problemáticas de interesse sobre como são realizadas as coberturas de mídia a respeito das temáticas, meio ambiente e suas interfaces na economia, na política e nas relações sociais de forma geral.

Nesse sentido, buscou-se apresentar estudo analítico crítico, de forma qualitativa da representação sobre o assunto, numa mídia estruturalmente coloca como autônoma do universo empresarial de mídias. Assim como ampliou-se a análise à luz de autores críticos e focados a partir dessa epistemologia de estudo.

Para tanto, a pesquisadora atuante do tema, Edna Ramos de Castro a região da Amazônia está inserida numa problemática social, cultural e econômica, em que se visualizam conflitos entre agentes do governo, setores privados e a localidade, imperando novamente práticas coloniais próximas das barbáries realizadas na colonização europeia, legitimando a naturalidade da exploração e roubo de recursos naturais e práticas culturais das comunidades (CASTRO, 2017, p.07).

Por isso, é de impacto social estudar as comunicações que denunciam, investigam e problematizam os assuntos ligados ao Meio Ambiente, em especial na região amazônica brasileira, em que se visualiza historicamente a falsa despretensão de agenciamentos políticos e econômicos na atuação de r̃desenvolvimentosòrurais e florestais, em detrimento de criarem desigualdades sociais e abusos ambientais irreversíveis às localidades. Dentre essas atuações midiáticas, destaca-se a Agência de Notícias r̃amazônia Realò que realiza aprofundamento das problemáticas sobre questões ambientas, indígenas e sociais na região amazônica.

A Agência de Notícias Amazônia Real é uma organização sem fins lucrativos e independente, financeiramente é mantida por recursos da Fundação Ford e, recentemente, pela Aliança pelo Clima e Uso da Terra (CLUA), além de outros parceiros. A Amazônia Real iniciou suas atividades em outubro de 2013 e mantém sua sede física em Manaus, no Amazonas. Apresenta as editorias de: Meio Ambiente; Povos Indígenas; Questão Agrária; Economia \& Negócios; Política e Cultura. Segundo o site da Agência se sustentam financeiramente por meio de doações, parcerias ï com entidades que desenvolvam responsabilidade socioambiental ï e projetos (AGÊNCIA, 2019).

Segundo a Agência Amazônia Real, o jornalismo que ela traz não se contradiz ao ñ....] poder econômico, em geral os detentores do monopólio do direito à informaçãoò (FARIAS, 2020). Para isso, contam com apoio financeiro de fundações internacionais, para manteremse economicamente viáveis e sustentáveis.

Pela característica de independência e da temática central ligar-se à crítica social e à investigação sobre o descaso com o contexto socioambiental na região amazônica, o presente 
artigo justifica-se pela abordagem jornalística pouco estudada sobre a Agência Amazônia Real, além da fundamentação teórica diferenciada que se pretende construir, a partir do jornalismo especializado em Meio Ambiente e Mudança Social na Amazônia brasileira. Por isso é importante destacar essa perspectiva de marco teórico, de um jornalismo em movimento, no desenvolver reportagens mais aprofundadas e analíticas sobre a questão socioambiental na região amazônica.

Em entrevista com a repórter e uma das representantes da Agência, Elaíze Farias, a Agência não é apenas um veículo de comunicação que realiza a cobertura sobre meio ambiente, e jornalismo ambiental. Com isso, Farias (2020) enfatiza a diversidade da cobertura de mídia da Agência, como um meio independente, investigativo e sediado na Amazônia, a qual aborda e desenvolve o jornalismo sobre o universo socioambiental.

Todas as reportagens da agência Amazônia Real fazem conexão entre a pauta ambiental e temas como justiça social, exclusão de populações tradicionais (povos indígenas, comunidades quilombolas, ribeirinhas, etc), desigualdades sociais causadas pelas ameaças ao meio ambiente trazidas por grandes empreendimentos, tais como agronegócio, mineração, rodovias, hidrelétricas, impactos das emergências climáticas nas populações amazônicas, etc. Apresentamos nas reportagens uma visão mais diversificada e complexa sobre as relações ambientais e sociais das populações locais e regionais e suas escolhas de vida. Contamos histórias de grupos sociais e étnicos ameaçados, impactados e vulneráveis frente às desigualdades; falamos da exploração devastadora de recursos naturais pelo sistema financeiro que só visa o lucro e do resultado de cinco séculos de colonização constante. Falamos sobre imigrantes, refugiados, violência contra crianças e mais recentemente também entramos com mais força nas questões de gênero, violência contra a muIher. (FARIAS, 2020).

Dessa perspectiva, os repórteres da Agência procuram se aproximar das comunidades locais, entrevistar escutando singularmente as histórias de vida, de denúncia e narrativas subalternizadas dessas localidades da Amazônia. As histórias são resgatadas como pontos de partida, para investigações sérias e em profundidade, trazendo por exemplo ñ...] casos de violações de direitos humanos, direitos territoriais, ameaças, invasões de terras públicas, desmatamentos, conflitos agrários, entre outros temas centraisò(FARIAS, 2020).

Para além do jornalismo, a Agência atua, desde 2015, em outra frente de trabalho. Realizaram círculos de debates sobre temáticas comuns à comunidade, como crise hídrica, mudanças climáticas e mineração em terra indígena e áreas protegidas da Amazônia, contaram com a colaboração de especialistas nos assuntos, além de representantes de comunidades ribeirinhas e indígenas das localidades circunvizinhas.

Três anos depois dessa iniciativa de debates, a Agência desenvolveu a primeira edição do projeto ñoficina Jovens Cidadãosò para o empoderamento de jovens no uso das tecnologias, da comunicação, da fotografia e das redes sociais digitais e no r̃omínio da segurança na internetò r̂Em 2018, a participação foi exclusiva de mulheres indígenas, vindas do interior do Amazonas, Rondônia e Roraima, além da capital Manaus. Em 2019, a oficina foi destinada apenas a rapazes indígenas, jovens que começam a despontar como lideranças de 
seus povosò(FARIAS, 2020). Nesse ano de 2020, Farias explica a pretensão da Agência para jovens quilombolas na participação dessas oficinas.

Como foco de atuação jornalística, a Agência visualiza na região amazônica muitas narrativas que precisam ser visibilizadas.

Nossa colaboração tem sido em contar história de um povo, de uma comunidade, de um grupo social cujas demandas precisam vir a público e que a maioria da população do país não conhece. São assuntos que nem sempre são populares ou fáceis de serem consumidos, mas extremamente necessários para a sociedade, para a democracia e para os próprios personagens. (FARIAS, 2020).

A necessária pauta jornalística, de forma crítica, sobre o Meio Ambiente e seu entorno socioeconômico faz parte também dos estudos do pesquisador Wilson da Costa Bueno em ñComunicação, Jornalismo e Meio Ambiente: teoria e pesquisaò Bueno (2007) ressalta a defesa pelo Meio Ambiente em confronto direto com os slogans de rMarketing verdeòe r̃ rustentabilidadeòque tentam consolidar na história o discurso de poder de parcela de investidores e de empresas ligadas às ações de estratégias destrutivas e corrosivas para o Planeta, aproveitando-se de atividades paliativas que tentam maquiar as reais intenções de suas produções econômicas.

Para tanto, a questão principal a ser analisada neste artigo compreende o tema socioambiental e seu entorno socioeconômico, no mês de fevereiro de 2019. Como metodologia de análise para esse conteúdo citado, utilizaram-se a Hermenêutica de Profundidade de Jonh B. Thompson (2011) aliada à Análise de Discurso (ORLANDI, 2010; MACHADO \& JACKS, 2001), focando uma análise qualitativa das reportagens da Agência.

\section{Metodologia}

O método da Hermenêutica de Profundidade - HP compreende observar a história a partir de uma visão ontológica, no caso deste artigo, relacionar a interface da HP com a Análise de Discurso - $A D$, no contexto do jornalismo na definição do conceito socioambiental, da Agência Amazônia Real em fevereiro de 2019.

Para os autores Bastos e Porto (2015, p.317) os pensadores deixam em suas ideias significados m̃ão ditosò por isso a importância da hermenêutica em ñnterpretar para preparar historicamente o pensamento futuroò(2015, p. 319). Outra tarefa do método é

[...] projetar num processo metateórico e metalinguístico uma unidade inter-relacional e analógica, interpretação simbólica da unidade, em que dimensões formam a organicidade ou a abrangência do todo numa interpretação também simbólica da realidade erigida pelo homem como r̃ser no mundoò Isto pois o lógos humano é interpretação simbólica da realidade e a linguagem hermenêutica é uma linguagem eminentemente simbólica. E, neste campo hermenêutico, a linguagem representa a 
relacionalidade de homem e mundo, quer dizer, o elemento comunitário-comunicativo no qual relacionamos nossas ideias e de uma forma verbalizada (BASTOS \& PORTO, 2015, p.319).

$\mathrm{Na}$ definição instrumental das hermenêuticas mais utilizadas, apropriou-se da Hermenêutica de Profundidade (HP) defendida por John B. Thompson (2011) na obra ñdeologia e Cultura Modernaò No capítulo sobre a HP Thompson esclarece a importância da contextualização social das formas simbólicas e suas características estruturais internas, assim como, o uso de outros métodos inter-relacionais à HP para a clareza dos fins de análise. Para o autor formas simbólicas são ñ...] construções significativas que exigem uma interpretação; elas são ações, falas, textos que, por serem construções significativas, podem ser compreendidasò (THOMPSON, 2011, p.357).

Thompson propõe três procedimentos principais ao referencial metodológico da HP. A Análise sócio histórica, a Análise Formal ou Discursiva e a Interpretação/Reinterpretação. Thompson define as seguintes subdivisões da Análise sócio histórica: Situações espaço temporais; Campos de interação; Instituições sociais; Estrutura social; Meios técnicos de transmissão; e para a Análise Formal ou Discursiva separa em: Análise semiótica; Análise da conversação; Análise sintática; Análise narrativa; Análise argumentativa (THOMPSON, 2011, p.365).

No primeiro passo para à análise da HP, identificado como análise sócio histórica o autor traz o entendimento que as formas simbólicas são itens produzidos, transmitidos e recebidos em condições históricas e sociais específicas. Logo, os objetivos principais desta análise [̃...] é reconstruir as condições sociais e históricas de produção, circulação e recepção das formas simbólicasò(THOMPSON, 2011, p.366).

A partir daí Thompson (2011, p.366-367) expõe que há situações espaço temporais específicas em que as formas simbólicas são produzidas e recebidas, assim como existem campos de interação em que essas formas simbólicas estão inseridas. Os campos de interação compreendem espaços, universos singulares em que se observa a ação e posicionamento de trajetórias, cujo movimento gera algumas das relações entre pessoas e provoca propostas entre elas (THOMPSON, 2011, p.366).

As situações espaço temporais podem ser caracterizadas, para esta análise das reportagens de Meio Ambiente na Amazônia Real, como o ambiente em que socialmente pertencemos, e também com a emergência de interrogações narrativas preocupadas com a exploração ambiental na Amazônia e entorno. Atualmente, o mundo está diante de mudanças contínuas (BAUMAN \& BORDONI, 2016). Somado ao momento atual, evidencias de ordem ecológicas apontam transmutações e, posicionamentos socioculturais necessários para a coexistência humana em coletivo. Uma sugestão atual é o movimento eco sustentável e cultural conceituado como lowsumerism, o qual consiste em consumir menos, viver com o que é realmente necessário, e tentar antes do consumo: trocar, consertar e fazer você mesmo. Como 
outros exemplos, tais como: ocupação dos espaços públicos e coletivos, aplicação de técnicas de permacultura, propostas de economia circular, e, projetos de financiamento coletivo com foco pró-ambiental, qualidade de vida, solidariedade, compartilhamento e cooperação.

$O$ resgate narrativo das reportagens sobre Meio Ambiente, assim como a identidade de onde se fala ï da região amazônica ï criticam a exploração do território amazônico e a desigualdade potencializada a partir dos conflitos advindos dessas explorações.

Avançando nos itens da HP, no procedimento sócio histórico, verificou-se a composição dos campos de interação, que estão dispostos com as instituições sociais. Na análise, os campos de interação são verificados a partir das oportunidades comunicacionais de denúncia e investigação, em relação às empresas que empreendem na região citada, muitas vezes de forma criminosa, assim como as reportagens provocam à crítica por meio das fontes testemunhais dos textos das reportagens, como àquelas comumente silenciadas e/ou problematizadas de forma inversa da história factual.

Já as instituições sociais são constituídas por recursos e regras mais estáveis e marcam as relações sociais inseridas em seu movimento interno (THOMPSON, 2011, p.367). Como instituições sociais visualizam-se os imaginários sociais sobre Meio Ambiente, a ideia Ambiental da Agência Amazônia Real lutar, denunciando e trazendo investigações de subtemas nas reportagens, explorando silenciamentos políticos, conflitos de território, poder cultural de minorias tradicionais, preservação de espécies e memória de representações jornalísticas do cenário ambiental. Essas relações sociais sobrepostas nos subtemas apontados compreendem o uso de fontes de pesquisa jornalístico testemunhal e primário, com os sujeitos e suas identidades no local, além de agirem a partir da definição de enfrentamento político e jurídico, quando necessário, com as relações dos agentes como: governo, órgãos de fiscalização, capital financeiro, intercâmbio de produção, empresas, comércio, agenciadores de produção, consumidores, locais, financiadores de mídia, patrocinadores, jornalistas, colunistas e publicidade de forma geral.

Diferenciando instituições sociais de estruturas sociais, Thompson identifica nas estruturas assimetrias e diferenças relativamente estáveis que caracterizam as instituições sociais e os campos de interação. ñAnalisar a estrutura social envolve tentativas de estabelecer os critérios, categorias e princípios que subjazem a essas diferenças e garantem seu caráter sistemático e durávelò Além de buscar compreender pelas assimetrias e diferenças sistemáticas a vida social (THOMPSON, 2011, p.367).

Nas estruturas sociais observam-se as reportagens sobre Meio Ambiente na Agência Amazônica Real como ancoradas na contra lógica da macroestrutura social de exploração ambiental em prol do desenvolvimento local, na afirmativa de gerar empregos, saneamento básico, indústrias e cultura de referência. As reportagens se contrapõem a essa ideia estrutural de todo desenvolvimento como progresso, bem como do entendimento da exploração local 
de territórios já ocupados, por etnias, cultura e modos de vida tradicionais. A Agência também encara o peso cultural da informação sobre Meio Ambiente dos veículos tradicionais de comunicação, que apresentam impacto na repercussão de audiência e saliência nas sociedades midiatizadas atualmente.

Os meios técnicos de transmissão são as mediações em que as formas simbólicas e mensagens chegam ao destino para as quais foram produzidas (THOMPSON, 2011, p.368). No exemplo desta análise, são quatro reportagens analisadas em fevereiro de 2019, da Agência Amazônia Real, na editoria de Meio Ambiente. O corpus de análise abarca as seguintes reportagens: ñustiça rejeita ação da Hydro Alunorte contra pesquisador Marcelo Lima, do IECò do dia 25 de fevereiro, ĩPrimatas são os mamíferos mais ameaçados da Amazôniaò do dia 21 de fevereiro, ז̃ jornalismo ambiental e científico da Amazônia perde Vandré Fonsecaò do dia 17 de fevereiro, e r̃̃uilombolas são excluídos por mineradora que causou crime ambiental no Paráò do dia 07 de fevereiro.

\subsection{Análise Discursiva}

Na Análise Formal ou Discursiva definiu-se a Análise Discursiva (THOMPSON, 2011, p.365) de perspectiva francesa, determinando a partir da análise das quatro reportagens o conceito central sobre Meio Ambiente, da Agência Amazônia Real. Seguindo para à análise do discurso das reportagens, focando o conceito de Meio Ambiente, delimitou-se para este artigo a formação discursiva como estratégia para à investigação.

Para o pesquisador e teórico da Análise do Discurso (AD), Dominique Maingueneau, em r̃os termos-chave da Análise do Discursoò (1997, p.50-1) as formações discursivas designam todo o sistema de regras que $\tilde{\eta}$.... fundam a unidade de um conjunto de enunciados dos sóciohistoricamente circunscritosò ou seja, a formação discursiva determina o que pode e deve ser dito, mas leva em conta para sua constituição as formações ideológicas dadas b a partir de uma posição e uma conjuntura histórica social dadas. Desse entendimento as pesquisadoras Marcia Benetti Machado e Nilda Jacks entendem as formações discursivas como ancoradas nas $\tilde{\eta}$....] formações ideológicas - também regras de existência, mas agora de estruturas de pensamentoò Pois a forma com que o indivíduo formula seu mundo deriva de um modo específico (MACHADO; JACKS, 2001, p.06).

Incluem-se aí a elaboração e o uso de conceitos sobre o mundo dos objetos e o próprio conhecimento, o posicionamento a respeito dos papéis ocupados historicamente pelos sujeitos, a visão do passado e do futuro, a consciência, ainda que difusa, a respeito do que desejamos ser e de como devemos agir, as noções de moral e de ética, enfim, tudo que pode ser sistematizado de forma mais ou menos estruturada como regras de visão, desejo e ação (MACHADO; JACKS, 2001, p.06).

Orlandi (2010, p.43) destaca dois pontos importantes da formação discursiva. A primeira parte da premissa de que o discurso se forma em seus sentidos, porque a fala que o 
sujeito diz se inscreve em uma formação discursiva, com isso passa a ter um sentido específico e não outro, aleatório. Nessa lógica permite afirmar que as palavras não apresentam um sentido nelas mesmo, mas derivam seus sentidos das formações discursivas em que se inscrevem.

As formações discursivas, por sua vez, representam no discurso as formações ideológicas. Desse modo, os sentidos sempre são determinados ideologicamente. [...] Tudo que dizemos tem, pois, um traço ideológico em relação a outros traços ideológicos. $E$ isto não está na essência das palavras, mas na discursividade, isto é, na maneira como, no discurso, a ideologia produz seus efeitos, materializando-se nele. $O$ estudo do discurso explicita a maneira como linguagem e ideologia se articulam, se afetam em sua relação recíproca (ORLANDI, 2010, p.43).

Contudo, vale ressaltar que a formação discursiva não se apresenta como blocos homogêneos, que funcionam independentes, são constituídas por um processo de contradição, são heterogêneas e apresentam suas fronteiras fluídas, num mecanismo de configurar-se e reconfigurar-se de acordo com suas relações (ORLANDI, 2010, p.44).

Outra questão importante que Orlandi destaca nesse primeiro ponto da formação discursiva é o entendimento de metáfora, como noção imprescindível no cenário da AD. Ela afirma que a metáfora não é considerada, como na retórica, como um termo que se trata de uma figura de linguagem, a metáfora na $A D$ é definida como ñtransferênciaòb tomada de uma palavra por outra $b$ desta forma a metáfora estabelece a maneira como as palavras significam. E é por meio dessa superposição (transferência), ñ...] que elementos significantes passam a se confrontar, de modo que se revestem de um sentidoò(PÊCHEUX apud ORLANDI, 2010, p.44). Portanto o sentido acontece precisamente em razão das relações de metáfora $b$ que se apresentam em forma de sinônimos, paráfrases, como efeito de substituição. Em decorrência dessas relações de metáfora a formação discursiva é historicamente um lugar provisório.

O outro ponto que Orlandi pontua na formação discursiva é sua importância sobre o ato de compreender, no funcionamento discursivo, os diferentes sentidos. Esclarece que palavras iguais podem ter significados diferentes, pois se inscrevem em formações discursivas que também são diferentes. Dá o exemplo da palavra ñerraò que para o índio tem um significado, para o agricultor outro, e para um agricultor sem-terra, outro ainda. Ou seja, a palavra ñerraòfoi usada em condições de produção diferentes, e para tanto, podem se apresentar em diferentes formações discursivas. Por isso que como método para o analista, no trabalho de análise deste artigo, deve se observar as condições de produção, ñ...] verificando o funcionamento da memória, ele $b$ o analista $b$ deve remeter o dizer a uma formação discursiva (e não outra) para compreender o sentido do que ali está ditoò(ORLANDI, 2010, p.45). 
Portanto é possível afirmar que a formação discursiva permite compreender o processo de produção dos sentidos, verificar sua relação com a ideologia e colaborar ao analista como estabelecer regularidade no funcionamento do discurso (ORLANDI, 2010, p.45).

\subsubsection{Memória do Jornalista}

Na reportagem ñ jornalismo ambiental e científico da Amazônia perde Vandré Fonsecaòtraz um resumo dos principais trabalhos do jornalista Fonseca, lembrando que ele era paulista e tinha 46 anos. Descrevem dados de sua morte em decorrência de parada cardíaca, e, trazem esclarecimentos sobre o enterro. Recuperam sua trajetória na Amazônia, onde vivia há 23 anos. Também resgatam comentários sobre ele, da vida pessoal e de trabalho, com fontes de entrevistas em que Vandré entrevistou, cinegrafistas, fotógrafos, editores, ativistas e parceiros. Dentre a memória como jornalista colaborador na Agência Amazônia Real, explicam que seu ingresso aconteceu em junho de 2017, desenvolvendo reportagens especiais sobre desmatamento da floresta, pontuando a situação da imigração venezuelana no País e a respeito dos abusos às comunidades tradicionais. îFez uma sequência de reportagens sensíveis e investigativas sobre a morte de crianças vítimas da raiva humana na Reserva Extrativista do Rio Unini, no Amazonas, tema que ele nunca deixou de acompanhar até antes de adoecerò(AGÊNCIA, 2019).

A reportagem de aproximadamente duas mil palavras, com fotografias do jornalista em atuação jornalística, baseia-se principalmente em falas de sujeitos que conviveram em atividades profissionais com Vandré, assim como essas informações estão ancoradas na formação discursiva (ORLANDI, 2010, p.43) que esses sujeitos representam no texto detalhado. $\mathrm{Na}$ formação discursiva das falas, e consequentemente, dos sujeitos, as ações em vida de Vandré estabelecem uma ligação de cuidado com o Meio Ambiente, nas investigações de temas, na preocupação com as fontes de pesquisa, na maioria os sujeitos locais, e na abordagem de denúncia e luta política constante em prol de um jornalismo investigativo de profundidade, de ética e de crítica. A respectiva formação ideológica, dos sentidos do discurso na reportagem, explora o conflito estabelecido do jornalismo ambiental de fato, de crítica e profundidade, na formação discursiva do trabalho de Vandré, com o jornalismo descritivo, muitas vezes, de descaso com os desdobramentos posteriores das denúncias e constatação de irregularidades na região amazônica.

\subsubsection{Ameaça na Amazônia}

Na reportagem r̃Primatas são os mamíferos mais ameaçados da Amazôniaòdo jornalista Vandré Fonseca, de aproximadamente mil e seiscentas palavras, é destacado os estudos do Instituto Chico Mendes de Conservação da Biodiversidade (ICMBio) em que notificam a ameaça de extinção na Amazônia de 36 espécies de mamíferos, das quais 16 são primatas e três deles estão em situação ainda mais grave, na faixa de r̃considerados extintosò 
No texto é problematizado a questão da extinção dos mamíferos na região amazônica e das ações humanas, políticas e econômicas legitimando o processo da ameaça ambiental. Das fontes de pesquisa e entrevistas trazidas na reportagem, pontuam-se dados do ICMBio, biólogo e coordenador do Centro Nacional de Pesquisa e Conservação de Primatas Brasileiros (CPB), dados da União Internacional para a Conservação da Natureza, coordenadora do Laboratório de Mamíferos Aquáticos do Instituto Nacional de Pesquisas da Amazônia (LMAInpa), dados da Lista Nacional Oficial de Espécies da Fauna Ameaçadas de Extinção e diretora de Pesquisa, Avaliação e Monitoramento da Biodiversidade do ICMBio.

Ao longo da reportagem há seis fotografias de mamíferos (macacos e botos) em extinção ï a fotografia do final do texto é uma galeria de fotos com outros mamíferos em extinção, como a onça pintada ï e um gráfico explicando os níveis de intensidade do processo de extinção na região.

As questões de discursividade (MAINGUENEAU, 1997) no texto da reportagem analisada correspondem as fundamentações de fontes de pesquisa de institutos ambientas renomados no País, tanto ao representarem o discurso ideológico de conservação ambiental, como de situarem-se em porta-vozes dessas representações, como administradores e especialistas ambientais. Outra ênfase discursiva é a recuperação de vários dados de estudos que denunciam e criticam os problemas correlacionados ao processo naturalizado de extinção dos mamíferos citados na pesquisa, indicando aos leitores a expressividade da ausência de políticas públicas com o descaso do Meio Ambiente.

\subsubsection{Informação e Censura}

Na reportagem de Moisés Sarraf: ñlustiça rejeita ação da Hydro Alunorte contra pesquisador Marcelo Lima, do IECAò a Agência informa sobre a vitória na justiça do pesquisador Marcelo de Oliveira Lima, do Instituto Evandro Chagas (IEC), em relação as explicações à população local de Barcarena sobre os acontecimentos de crime ambiental dos rejeitos químicos advindos do vazamento da mineradora norueguesa Hydro Alunorte em fevereiro do ano passado. No texto destacam os dizeres do juiz federal Rubens Rollo D囚liveira, da 3 ${ }^{\text {a }}$ Vara do Pará, expondo que Lima cumpriu com sua função r̃̃le informar a população acerca dos acontecimentos ocorridos em Barcarenaò

$\mathrm{Na}$ reportagem de aproximadamente duas mil palavras, com a utilização de cinco fotografias sobre o tema, Sarraf traz as fontes do pesquisador Marcelo Lima, dados do Instituto Evandro Chagas de pesquisas dos rejeitos do entorno da Hydro Alunorte e de novos pareceres de problemas humanos advindos dos rejeitos nos igarapés locais, além dos dados do Ministério Público sobre o caso e da própria sentença do juiz.

Na relação recíproca (ORLANDI, 2010) entre discurso e ideologia, o conteúdo da reportagem enfatiza o descaso ambiental da empresa norueguesa em Barcarena, delimitando 
seu papel disfuncional como viabilizadora de empreendimento local e ambiental, em decorrência do sentido discursivo de ter sido derrotada na justiça brasileira pelo compromisso ético e público do pesquisador do IECA, também por tentar censurar as informações a respeito da contaminação por bauxita e outros rejeitos à cidade, anunciadas no laudo pericial da equipe do pesquisador, solicitado pelo Ministério Público em 2018. A discursividade no texto demarca a desconstrução representacional de poderes econômicos ï caso da Hydro Alunorte ï quando os mesmos pretendem inverter as ordens de opressor e oprimido, no exemplo, do explorador e da comunidade explorada.

\subsection{4. À margem do seu território}

Na reportagem r̃̃uilombolas são excluídos por mineradora que causou crime ambiental no Paráòdesenvolvida pela jornalista Catarina Barbosa, denuncia o abandono de 900 famílias que residem na comunidade quilombola Cupuaçu/Boa Vista, no Pará. A localidade foi atingida diretamente em fevereiro de 2018, pelo vazamento de rejeitos químicos da mineradora Hydro Alunorte. A denúncia também explora o problema da falta de água potável da comunidade, que foi excluída do programa de indenização da Hydro Alunorte. ז̃ cadastro de atingidos que viviam na bacia hidrográfica dos rios Pará, Murucupi e São Francisco foi feito pela empresa e deixou de fora, sem maiores justificativas, os quilombolas. No próximo dia 17 completa 1 ano que o transbordamento do Depósitos de Resíduos Sólidos (DRS1) aconteceuò (BARBOSA, 2019).

Em razão do crime ambiental a empresa Hydro Alunorte foi multada em $\mathrm{R} \$ 20$ milhões pelo lbama, em que $\mathrm{R} \$ 10$ milhões foi em decorrência de atividade potencialmente poluidora sem licença válida da autoridade ambiental e a outra parte por r̃operar tubulação de drenagemòsem licença.

Com aproximadamente dois mil, trezentos e cinquenta palavras a reportagem traz sete fotografias representativas das fontes entrevistadas e da localidade. Das fontes, a jornalista traz o depoimento de locais, em suas observações sobre os problemas de pele, de pulmão, infecção e outros agravamentos de saúde pelo afetamento dos resíduos na comunidade quiIombola, além da entrevista com a agricultora Odilene Raiol, da Comunidade Cupuaçu/Boa Vista, de dados de dois laudos do Instituto Evandro Chagas, dos laudos da Hydro Alunorte das empresas SGW e Atecel, informações do Ministério Público Estadual do Pará, da liderança da comunidade de Vila Nova, em Itupanema, Ângela Maria Vieira, da assessoria da Hydro Alunorte, do depoimento de Mário Assunção do Espírito Santos, pedagogo e liderança da comunidade quilombola Gibirié de São Lourenço, de informações do site G1 sobre o caso do crime ambiental no mesmo local pela empresa em 2009, do quilombola José Augusto do Santos Freitas, membro da diretoria da associação de remanescentes de quilombolas Gibirié de São Lourenço, e seu de pai, que vivia da pesca local. 
O fato gerador de interesse no discurso é a questão central da marginalização da comunidade quilombola, de aproximadamente 900 famílias, dos recursos ambientais naturais que elas precisam e detinham antes do crime ambiental de 2009 e 2018 pela Hydro Alunorte. Desses recursos há a água potável (para alimentação, higiene e pesca) e o uso do solo para agricultura, ambos direitos de território dessas comunidades tradicionais. As formações discursivas (MAINGUENEAU, 1997) dos depoimentos dos representantes da comunidade, assim como de outros locais quilombolas, potencializa o discurso enunciativo de suas vivências e construções históricas culturais, reafirmando o sentido problematizador da denúncia da reportagem, bem como do descaso de crime ambiental a partir da voz daqueles que ainda sofrem com os prejuízos de contaminação da água e do solo. Em contraponto ouve-se também no texto a contextualização da empresa, pela assessoria, pelos laudos publicados e outras informações de veículos de comunicação, no caso do crime ambiental de 2009. Ou seja, há a preocupação do constructo analítico da reportagem pelo confronto do discurso de onde se fala e das vozes concorrentes, na discursividade e formação ideológica formada.

\section{Resultados e Discussão}

Após essa análise, desenvolveu-se a interpretação e reinterpretação. Thompson descreve a interpretação como o momento do método de explicar interpretando sobre o que é dito e representado, fazendo justiça aos construtos situados social e historicamente dos objetos em foco (2011, p.377).

Nas quatro reportagens analisadas da editoria de Meio Ambiente reforçam o olhar de impacto sobre o conceito socioambiental, três reportagens denunciam em profundidade problemas ambientais na região amazônica, uma sobre o descaso do crime ambiental da Alunorte com a comunidade quilombola de Boa Vista e região, outra sobre a extinção de mamíferos na Amazônia, e a terceira enfatiza a inversão de valores a respeito da Hydro Alunorte contra o pesquisador do Instituto Evandro Chagas. A quarta reportagem sobre a memória do jornalista ambiental Vandré Fonseca, de uma forma secundária, identifica os temas de denúncia e investigação sobre a conservação do Meio Ambiente na Amazônia pelas atividades jornalísticas de sua carreira profissional.

As formações discursivas das reportagens potencialmente propõem o sentido de enfrentamento à exploração ambiental e descaso político econômico na região amazônica, promovendo ideologicamente seu papel (de veículo de comunicação independente) de interlocutor do Meio Ambiente com o público, a partir de matrizes de mudança cultural pela investigação jornalística e aprofundamento com as fontes primárias, locais e de pesquisa científica.

As reportagens trazem fontes de pesquisa que costumam estar abertas ao público e a outros jornalistas, como laudos científicos, dados de assessorias, pesquisas de institutos e 
pareceres do Ministério Público e Meio Ambiente. Ou seja, a profundidade sobre essas temáticas depende da articulação profissional do jornalista em apurar, correlacionar, confrontar dados e investigar declarações, com a função de aprofundar, interpretando e prospectando.

Da questão do Meio Ambiente há notável conteúdo a partir de apurações desses órgãos e pesquisas de institutos, o que costuma faltar são iniciativas de apuração e aprofundamento por parte do jornalismo ambiental e socioambiental. Como recurso jornalístico, as reportagens também buscaram fontes de entrevistas primárias, com jornalistas, fontes locais, quilombolas, agricultores, ativistas e lideranças, depoimentos que colaboraram para a lógica da comunicação que privilegia a história, a narrativa, a exploração dos fatos por aqueles que estão à frente do processo gerador de interesse, o que chamamos em técnicas de jornalismo de fontes primárias e testemunhais.

Os discursos jornalísticos das reportagens analisadas situam-se em narrativas prósocioambiental, no sentido de pertencimento ao local para o qual lutam e denunciam, utilizando-se de oportunidades comunicacionais de testemunhas e investigação em apurar, a partir da independência da Agência Amazônia Real como instituição autônoma, mas, ideologicamente alinhada à contra lógica das estruturas sociais atuais, que ainda tendem a primar pela economia de mercado em detrimento das localidades e culturas tradicionais da região amazônica, sem colocarem-se como ativistas.

\section{Considerações Finais}

A Agência Amazônia Real disponibiliza o conteúdo disposto no site para possíveis republicações livres em outros meios de comunicação e comunicações, fato que garante o acesso à informação (citação da fonte de pesquisa) a partir desse olhar socioambiental sobre a região amazônica. Segundo a Agência, ñ...] apoiamos ao máximo a plena democratização da informaçãoò (FARIAS, 2020).

O conceito socioambiental nas reportagens analisadas está ancorado em discursos de aprofundamento, denúncia, investigação e luta política em conservar o ambiente, o território e o cuidado com a natureza da região amazônica. Para isso os textos jornalísticos trazem o recurso de diversidade de fontes, primárias, de pesquisa, e de confronto, problematizando a complexidade inerente à organização discursiva dos textos jornalísticos de interpretação e prospecção de promoção à alteridade.

Nessa lógica de abordagem, o contato com a fonte, traz também o resgate da história desses personagens, suas narrativas e conflitos, segundo Elaíze Farias ñOuvimos mais do que falamosò(2020).

Nos resultados apresentados, verificou-se também o olhar da Agência Amazônia Real, para temas de denúncia, expressivamente relevantes para a sociedade, que costumam ser diluídos na cobertura da mídia tradicional e mesmo esquecidos por ela. Outro fator de impacto 
ético na conduta do jornalismo, é o acompanhamento de processos judiciais, verificando e apurando seus desdobramentos até que as ações sejam finalizadas nos tribunais de justiça do País (FARIAS, 2020).

Para a Agência (FARIAS, 2020) T̃houve sempre uma cobertura jornalística muito desigual sobre temas como hidrelétricas, mineração, garimpo, agronegócio, flexibilização de direitos territoriais, especulação de terra, grilagem, etc, atividades que impactam a vida das populações mais marginalizadasò A Agência Amazônia Real definiu visibilizar esses grupos sociais, até então subalternizados e por muitas vezes reduzidos aos seus estereótipos e simplismos.

Para a pesquisadora Ângela Arruda (2002) a alteridade se baseia justamente no respeito do outro a partir de suas diferenças (distanciando do rótulo), acolhendo-as; logo, os textos sobre assuntos socioambientais da Agência, trazem para o debate as complexidades desses sujeitos nas formações discursivas. Inquietando nas narrativas olhares e vozes antes silenciados. O sentido ideológico de não homogeneizar (GOMES, 2014), portanto, essas diferenças nas narrativas, também possibilita o caminho para um conceito socioambiental em articulação constante com os sujeitos nesses territórios, proporcionando empoderamento aos representados nesses depoimentos e nessas histórias de vida, potencializando, assim, o valor do local de onde se fala com interlocutores ativos e independentes, porém, alinhados aos seus espaços de pertencimento e identidade. Prospecções para outros estudos.

\section{Referências}

AGÊNCIA Amazônia Real. ĩ jornalismo ambiental e científico da Amazônia perde Vandré Fonsecaòin Agência Amazônia Real, 2019. Disponível em: http://amazoniareal.com.br/o-jornalismo-ambiental-e-cientifico-da-amazonia-perde-vandre-fonseca/. Acessado em: 08 de março de 2019.

ARRUDA, A. (org.). Representando a alteridade. 2 ed. Petrópolis, Rio de Janeiro: Vozes, 2002.

BARBOSA, Catarina. r̃Quilombolas são excluídos por mineradora que causou crime ambiental no Paráòin Agência Amazônia Real. Disponível em: http://amazoniareal.com.br/quilombolassao-excluidos-por-mineradora-que-causou-crime-ambiental-no-para/. Acessado em: 08 de março de 2019.

BASTOS, F. \& PORTO, S. D. Análise Hermenêutica, in: DUARTE, J.; BARROS, A. (Orgs). Métodos e Técnicas de Pesquisa em Comunicação. 2 ed. São Paulo: Atlas, 2015.

BAUMAN, Z. \& BORDONI, C. Estado de Crise. Rio de Janeiro: Zahar, 2016.

BUENO, Wilson da Costa. Comunicação, Jornalismo e Meio Ambiente: teoria e pesquisa. São Paulo: Mojoara Editorial, 2007. 
CASTRO, Edna Ramos de (Orgs.) Territórios em transformação na Amazônia - saberes, rupturas e resistências. Belém: NAEA, 2017. Disponível em: https://cpalsocial.org/documentos/706.pdf. Acessado em 02 de março de 2019.

FARIAS, Elaíze. Entrevista concedida para o artigo îPerspectiva socioambiental no discurso jornalístico do site da Agência Amazônia Realò Arquivo documental. Março de 2020.

FONSECA, Vandré. T̃Primatas são os mamíferos mais ameaçados da Amazôniaòin Agência Amazônia Real, 2019. Disponível em: http://amazoniareal.com.br/primatas-sao-os-mamiferos-mais-ameacados-da-amazonia/. Acessado em 08 de março de 2019.

GOMES, Ingrid. The coverage of Islam - marginalized and moralizing narratives. Intercom: Revista Brasileira de Ciências da Comunicação, 37(1), 71-89, 2014. Disponível em: https://dx.doi.org/10.1590/S1809-58442014000100004. Acessado em 08 de março de 2019. HOLMGREN, D. Permacultura: princípios e caminhos além da sustentabilidade. Tradução Luzia Araújo. Porto Alegre: Via Sapiens, 2013.

LOWSUMERISM. Disponível em: https://www.youtube.com/watch?v=jk5gLBlhJtA. Acessado em: 03 de março de 2019.

MACHADO, Márcia Benetti \& JACKS, Nilda Aparecida. O discurso jornalístico. Anais do X Encontro Anual da Associação Nacional dos Programas de Pós-Graduação em Comunicação ï Compós. Brasília: UNB, 2001.

MAINGUENEAU, Dominique. Os termos-chave da análise do discurso. Lisboa: Gradiva, 1997.

ORLANDI, Eni P. Análise de Discurso ï Princípios e Procedimentos. 9 ed. Campinas-SP: Pontes Editores, 2010.

SARRAF, Moisés. ñustiça rejeita ação da Hydro Alunorte contra pesquisador Marcelo Lima, do IECAòin Agência Amazônia Real, 2019. Disponível em: http://amazoniareal.com.br/justica-rejeita-acao-da-hydro-alunorte-contra-pesquisador-marcelo-lima-do-iec/. Acessado em 08 de março de 2019.

THOMPSON, J. B. Ideologia e Cultura Moderna. Teoria social crítica na era dos meios de comunicação de massa. 9 ed. Petrópolis-RJ: Editora Vozes, 2011. 